\title{
Functional dementia assessment using a video monitoring system: Proof of concept
}

\author{
E. Mulin $\mathrm{MD}^{1,2}$, V. Joumier $\mathrm{MSc}^{2,3}$, I. Leroi $\mathrm{MD} \mathrm{PhD}^{4}$, J.H. Lee $\mathrm{MSc}^{1,3}$, \\ J. Piano MSc ${ }^{1,3}$, N. Bordone MSc ${ }^{1}$, A. Derreumeaux MSc ${ }^{3}$, P. Malléa $\mathrm{PhD}^{3,5}$, \\ P. Brocker $\mathrm{MD}^{6}$, A. Dechamps $\mathrm{PhD}^{1,3}, \mathrm{R}$. Romdhane $\mathrm{PhD}^{2}$, \\ M. Thonnat $\mathrm{PhD}^{2}$, F. Bremond $\mathrm{PhD}^{2,3}$, R. David MD PhD ${ }^{1,3}, \mathrm{P} . \mathrm{H}$. Robert MD PhD ${ }^{1,3}$
}

${ }^{1}$ Centre Mémoire de Ressources et de Recherche, CHU Nice, France; ${ }^{2}$ Pulsar team, INRIA, France; ${ }^{3} \mathrm{EA}$ CoBTeK, University of Nice Sophia Antipolis, France; ${ }^{4}$ Lancashire Care Foundation NHS Trust/University of Manchester, UK; ${ }^{5}$ CNR Santé à domicile et autonomie, France; ${ }^{6}$ Geriatric department, CHU Nice, France

E: probert@unice.fr

\begin{abstract}
E. Mulin, V. Joumier, I. Leroi, J.H. Lee, J. Piano, N. Bordone, A. Derreumeaux, P. Malléa, P. Brocker, A. Dechamps, R. Romdhane, M. Thonnat, F. Bremond, R. David, P.H. Robert. Functional dementia assessment using a video monitoring system: Proof of concept. Gerontechnology 2012;10(4):244-248; doi:10.4017/gt.2012.10.4.005.00 Functional assessments of a person's ability to perform activities of daily living (ADL) currently involves clinical rating scales. These scales are limited in providing objective and sensitive information. Aim To develop an automated tool for objective and quantitative assessment of functional ability in Alzheimer disease (AD). Methods 16 patients with mild to moderate AD (age=76.7 $\pm 4.0, M M S E=20,7 \pm 2.0)$ and 10 age and gender matched healthy controls (HC; age $=73.9 \pm 4.5, M M S E=28.1 \pm 1.3$ ) were evaluated clinically, cognitively, and functionally. Subsequently, each subject was asked to perform a set of daily tasks while monitored by two video cameras. A measure of functional impairment was then computed from quantitative and qualitative parameters collected from video recordings that were first annotated by two clinicians (blind to each other's results and the participants' clinical state). Results The VMS (Video monitoring system) function index (derived from a ratio of efficacy in ADLs) correlated strongly with cognitive results (MMSE, Rho=0.81) as well as with IADL-E scores (Rho=-0.65). Conclusion This study is a successful proof of concept for a novel assessment tool in dementia. The derived VMS function-index may provide a pragmatic, objective and continuous measure of cognitive and functional ability for clinical assessments as well as having a role as an outcome measure in clinical trials. Future research should complete the automation of the method.
\end{abstract}

\section{Keywords: Alzheimer disease diagnostics, ICT, VMS-functional index}

Alzheimer disease (AD) and related dementias represent a major challenge for health care systems in aging populations. In $\mathrm{AD}$, 'dementia' is diagnosed when the disease has reached the stage that the cognitive or behavioural (neuropsychiatric) symptoms interfere with social functioning or instrumental activities of daily living ${ }^{1}$. The current standard of clinical assessment relies on (i) questions posed to caregivers using retrospective recall of events at home, (ii) some standardized rating scales or observations by a trained occupational therapist of (iii) a patient's performance during daily leisure and living activities. The Alzheimer's disease Assessment Scale Cognitive subscale (ADAS-
$(\mathrm{Cog})$, is the primary neuropsychological outcome measure for most intervention trials in $A D^{2}$. These techniques cannot provide an accurate, objective and continuous measure of functional ability, and may not adequately identify responses to therapy or address other outcomes ${ }^{3,4}$. Functional ability has impact on all aspects of the disease manifestation as well as on several caregiver aspects, and could be a more sensitive marker of disease progression or treatment response.

The National Institute on Aging and Alzheimer's Association workgroup ${ }^{5}$ recommended that 'functional impairment' be used to diagnose all causes of dementia in a clinical set- 


\section{Functional dementia assessment}

ting. Techniques involving imaging and video processing enable a study of patients' performances and actions in real time and real life situations. Focussing ICT (Information and Communication Technology) methods on caregiver-clinician-patient desired functional outcomes may provide clinically relevant information on responses to treatment as well as enable an accurate diagnosis of dementia. Furthermore, unanticipated changes that conventional psychometric measures may fail to capture, can be identified by such methods ${ }^{6}$.

Our aim is to develop an automated, pragmatic, objective and quantifiable behavioural and functional assessment score for $A D$ and related disorders.

The study was approved by the Nice Ethics Committee. Only participants with capacity to consent to the study were included. Each participant gave informed consent before the first assessment.

\section{Study participants and clinical assessment}

16 ambulatory AD patients and their caregivers, as well as 10 healthy control participants were included in the study. The two groups did not differ in gender or age (Table 1). AD patients were consecutively recruited from the Nice Memory Center by geriatricians EM and PHR. Inclusion criteria were: (i) a diagnosis of probable AD according to NINCDS-ADRDA criteria ${ }^{7}$, and (ii) Mini-Mental State Examination score $(\mathrm{MMSE})^{8}$ above 20. Patients with significant mo-

\section{Methods}

tor disturbances, based on clinical examination by a neurologist, were excluded. Healthy control participants were recruited from caregivers and volunteers who were participating in other trials and matched in age and gender with the AD group.

Prior to the VMS (Video Monitoring System) session, an independent clinician assessed all subjects for (i) global cognitive functioning with the MMSE, (ii) apathy and depression with the Apathy Inventory $(\mathrm{Al})^{9}$ and the Montgomery Asberg Depression Rating Scale (MADRS) ${ }^{10}$, (iii) participants' caregivers' perception of behaviour with the Neuropsychiatric Inventory 12 -items $(\mathrm{NPI})^{11}$, and (iv) functional ability with the Instrumental Activities of Daily Living scale (IADL-E) ${ }^{12}$. Patients and healthy controls differed greatly in cognitive and behavioural parameters, but not in the depression assessment (Table 1).

\section{Experimental site and scenario}

In the geriatric department of Nice University Hospital, an observation room was equipped with everyday objects, such as an armchair, a table, a tea corner, a television (TV), a personal computer (PC), and a bookcase. Two fixed monocular video cameras (8 frames/seconds) were installed to capture activities of subjects, when undertaking a predetermined list of 10 daily activities in a given order, as follows:

-Walk to the reading table to read during 2 min; -Walk to the tea corner where the kettle is and boil water for tea;

-Walk to the phone to enter this number: $x x x x x x$; -Take the watering can and water the plant;

-Walk to the television and turn it on with the remote control;

-Walk to the reading table, take the playing cards and classify them by colour;

Table 1. Demographics and clinical characteristics of the AD (Alzheimer disease) group and healthy control group; MMSE=Mini-Mental State Examination; IADL-E=Instrumental Activity of Daily Living Evaluation; Al=Apathy Inventory; MADRS=Montgomery Asberg Depression Rating Scale; NPI=Neuropsychiatric Inventory; confidence level 0.05; ${ }^{a}=n=15$; ${ }^{*}=p<0.001^{* *}=p<0.01$

\begin{tabular}{|c|c|c|c|c|}
\hline \multirow[t]{2}{*}{ Variable } & \multicolumn{2}{|c|}{$\begin{array}{l}\text { AD ambulatory patients } \\
\qquad(n=16)\end{array}$} & \multicolumn{2}{|c|}{$\begin{array}{l}\text { Healthy controls } \\
\qquad(n=10)\end{array}$} \\
\hline & Mean & $\mathrm{Cl}(95 \%)$ & Mean & CL(95\%) \\
\hline Mean age, yrs & 76.7 & $72.7-80.7$ & 73.9 & $69,4-78,4$ \\
\hline MMSE* & 20.7 & $18.7-22.7$ & 28.1 & 26.8-29.4 \\
\hline IADL-E** & 14.3 & $11.2-17.5$ & 10.5 & $9.7-11.3$ \\
\hline $\mathrm{Al}^{*}$ & 2.3 & $0.9-3.8$ & 0 & - \\
\hline MADRS & 4.3 & $1.9-6.7$ & 3.5 & $0.3-6.7$ \\
\hline \multirow[t]{2}{*}{$\mathrm{NPI}$} & 13.6 & $8.1-18.9^{a}$ & Not done & - \\
\hline & $\mathbf{n}$ & $\%$ & $\mathbf{n}$ & $\%$ \\
\hline Number of females & 11 & 69 & 5 & 50 \\
\hline
\end{tabular}

ake the green 'ABCD' folder from the desk with the ABCD sheets in it;

-Match the ABCD sheets from the folder to the one's dispersed over the room;

-Put the 'ABCD' folder back on the desk;

After instruction of the subject, and prior to leaving the observation room, the examiner (i) wrote down each item of the scenario to follow by the subject with the location and use of relevant objects, (ii) checked if the subject understood the tasks, and (iii) informed the subject that the examiner -Leave the room. 


\section{Functionaldementia assessment}

remained available for answering questions. The subject kept a list of instructions for use during the assessment. A total of 20 min was allowed for completing the scenario. The subject could leave the observation room earlier when s/he felt that the required tasks were completed, or when s/he just chose to do so. An examiner located outside of the room monitored the safety of the subject.

\section{Functional impairment score development}

Following each recording session, two independent clinicians who were blind to the participant's cognitive and clinical status, independently viewed the video twice, analysing subject's gait, posture, position in the room, and interaction with objects in order to assess each activity, and compute the ratio of efficacy: $\mathrm{RE}_{\mathrm{ff}}=$ time spent by the subject in performing the listed activities / total time spent in the room.

With a pragmatic and empirical approach, four activity parameters $\left(k_{1-4}\right)$ were defined with a high likelihood of corresponding to functional decline. Five clinicians (two psychiatrists, one neurologist, two geriatricians) were asked to rate these parameters independently in order to increase the clinical importance (from the most to the least important: (i) omission of one of the activities $\left(\mathrm{k}_{1}\right)$; (ii) repetition of the same activity $\left(\mathrm{k}_{2}\right)$; (iii) incorrect order of performed activities $\left(k_{3}\right)$; and (iv) number of attempts before completing a given activity $\left(k_{4}\right)$. This led to a functional impairment score S:

$$
\begin{array}{lr}
S\left(k_{1}, k_{2}, k_{3}, k_{4}\right)(j)=\left[R E_{f f}(j)\right] \times\left[k_{1}{ }^{a 1(j)} \times k_{2}{ }^{a 2(j)} \times k_{3}{ }^{1-a 3(j)} \times k_{4}{ }^{a 4(j)}\right] \\
\operatorname{lndex}_{0}(j)=R E_{f f}(j) & {[1]} \\
\text { Index }_{1}\left(k_{1}\right)(j)=R E_{f f}(j) \times\left[k_{1}^{a 1(j)}\right] & {[2]} \\
\text { Index }_{2}\left(k_{1}, k_{2}\right)(j)=R E_{f f}(j) \times\left[k_{1}{ }^{a 1(j)} \times k_{2}{ }^{a 2(j)}\right] & {[4]} \\
\text { Index }_{3}\left(\left(k_{1}, k_{2}, k_{3}\right)(j)=R E_{f f}(j) \times\left[k_{1}{ }^{a 1(j)} \times k_{2}{ }^{a 2(j)} \times k_{3}{ }^{1-a 3(j)}\right]\right. & {[5]}
\end{array}
$$$$
\text { where }
$$$$
\mathrm{j} \text { is a given subject }
$$$$
k_{1-4} \text { is the model parameter set with weights }
$$$$
0<\mathrm{k}_{1}<\mathrm{k}_{2}<\mathrm{k}_{3}<\mathrm{k}_{4}<1 \text {, }
$$$$
\mathrm{RE}_{\mathrm{ff}} \text { is the ratio of efficacy, }
$$

a1(j) is the number of omissions,

a2(j) is the number of repetitions,

a3(j) is a binary value equal to 1 if the subject undertook all activities in the correct order, or 0 if not,

$\mathrm{a} 4(\mathrm{j})$ is the number of attempts before completing an activity.

\section{Fitting procedure for $\mathbf{k}_{\mathbf{1}-\mathbf{4}}$}

\section{Model parameter set generation}

50,000 different combinations of parameter values, consistent with constraints of order and defined by the independent clinicians, were drawn up using a random number generator for each model parameter set $i,(1)$ four random variables $U_{1(\mathrm{i})}, U_{2(\mathrm{i})}, U_{3(\mathrm{i}) !} U_{4(\mathrm{i})}$ independent and identically distributed (i.i.d) were generated, following a uniform distribution $[0,1]$. A model parameter set $\mathrm{i}\left(\mathrm{k}_{1(\mathrm{i})}, \mathrm{k}_{2(\mathrm{i})}, \mathrm{k}_{3(\mathrm{i})}, \mathrm{k}_{4(\mathrm{i})}\right)$ was obtained according to the following equations (consistent with the constraints of order $\left.\mathrm{k}_{1(\mathrm{i})}<\mathrm{k}_{2(\mathrm{i})}<\mathrm{k}_{3(\mathrm{i})}<\mathrm{k}_{4(\mathrm{i})}\right)$ :

$$
\begin{aligned}
& k_{1(i)}=u_{1(i)[0,1]} \\
& k_{2(i)}=k_{1(i)}+\left(1-k_{1(i)}\right) u_{2(i)[0,1]} \\
& k_{3(i)}=k_{2(i)}+\left(1-k_{2(i)}\right) u_{3(i)[0,1]} \\
& k_{4(i)}=k_{3(i)}+\left(1-k_{3(i)}\right) u_{4(i)[0,1]} \\
& \text { where }
\end{aligned}
$$

$\mathrm{u}_{1(\mathrm{i})[0,1],} \mathrm{u}_{2(\mathrm{i})[0,1],} \mathrm{u}_{3(\mathrm{i})[0,1]}, \mathrm{u}_{4(\mathrm{i})[0,1]}$ are the realizations of random variables $\mathrm{U}_{1(\mathrm{i})}, \mathrm{U}_{2(\mathrm{i})}, \mathrm{U}_{3(\mathrm{i})}, \mathrm{U}_{4(\mathrm{i})}$, respectively.

\section{Model parameter set selection}

We pre-selected model parameter sets according to a criterion distance based on Spearman correlation coefficients, $\rho_{\text {Spearman, }}$ between a score associated with model parameter $i$ and both MMSE and IADL-E: $\rho_{\text {Spearman }}\left(S\left(k_{1(i)}, k_{2(i)}, k_{3(i)}, k_{4(i)}\right), M M S E\right)$ and $\rho_{\text {Spearman }}\left(S\left(k_{1(i)}, k_{2(i)}, k_{3(i)}, k_{4(i)}\right), I A D L-E\right)$. We qualified a model parameter set $\mathrm{i}$ as producing a 'good fit', if it checks simultaneously conditions $\mathrm{C} 1$ and C2:

\section{C1: $\rho_{\text {Spearman }}\left(S\left(k_{1(i)}, k_{2(i)}, k_{3(i)} k_{4(i)}\right), \quad M M S E\right)>$} $\beta_{(M M S E, 0.75)}\left(S\left(k_{1}, k_{2}, k_{3}, k_{4}\right)\right)$

C2: $\rho_{\text {Spearman }}\left(S\left(k_{1(i)}, k_{2(i)}, k_{3(i)}, k_{4(i)}\right), \quad I A D L-E\right)<$ $\beta_{(\text {IADL-E, } 0.25)}\left(S\left(k_{1}, k_{2}, k_{3}, k_{4}\right)\right)$ where

$\beta_{(M M S E, 0.75)}\left(S\left(k_{1}, k_{2}, k_{3}, k_{4}\right)\right)$ is the $75^{\text {th }}$ centile of the distribution of the Spearman coefficient correlation between the score associated with a model parameter set and MMSE,

$\beta_{\text {(IADL-E, } 0.25)}\left(S\left(k_{1}, k_{2}, k_{3}, k_{4}\right)\right)$ is the $25^{\text {th }}$ centile of the distribution of the Spearman coefficient correlation between the score associated with a model parameter set and IADL-E.

In total 939 parameter sets met simultaneously requirements $\mathrm{C} 1$ and $\mathrm{C} 2$. The model parameter set $\left(\mathrm{K}_{1-4}\right)$ consists of the mean of the selected parameters (Table 2).

Table 2. Descriptive statistics of 939 combinations of $k_{1}=$ activity missed; $k_{2}=$ activity repeated; $k_{3}=$ incorrect order; $k_{4}=$ first attempt incorrect

\begin{tabular}{c|cccccc}
\hline Parameter & Minimum & $\mathbf{1}^{\text {st }}$ Quartile & 3 $^{\text {rd }}$ Quartile & Maximum & Mean & SD \\
\hline$k_{1}$ & 0.655 & 0.736 & 0.790 & 0.852 & 0.764 & 0.0380 \\
$\mathrm{k}_{2}$ & 0.753 & 0.815 & 0.863 & 0.924 & 0.839 & 0.0324 \\
$\mathrm{k}_{3}$ & 0.787 & 0.856 & 0.899 & 0.932 & 0.876 & 0.0296 \\
$\mathrm{k}_{4}$ & 0.827 & 0.913 & 0.952 & 0.999 & 0.931 & 0.0302 \\
\hline
\end{tabular}




\section{Functionaldementia assessment}

Table 3. VMS (Video Management System) ratio of efficacy (RE ff $)$ and qualitative parameters of the $A D$ (Alzheimer disease) group and healthy control group; $R E_{f f}=$ Ratio of efficacy; $p<0.05$

\begin{tabular}{l|cccc}
\hline \multirow{2}{*}{$\begin{array}{l}\text { At least one activity } \\
\text { failure of category: }\end{array}$} & \multicolumn{2}{|c}{$\begin{array}{c}\text { AD ambulatory } \\
\text { patients }(\mathbf{n = 1 6 )}\end{array}$} & \multicolumn{2}{c}{$\begin{array}{c}\text { Healthy controls } \\
(\mathbf{n = 1 0})\end{array}$} \\
\cline { 2 - 5 } & $\mathbf{n}$ & $\mathbf{\%}$ & $\mathbf{n}$ & $\mathbf{\%}$ \\
\hline Missed & 2 & 13 & 0 & 0 \\
Repeated & 6 & 38 & 0 & 0 \\
Incorrect order & 4 & 25 & 0 & 0 \\
First attempt incorrect & 7 & 44 & 1 & 10 \\
\hline Construct & Mean & $\mathbf{C l}(\mathbf{9 5} \%)$ & Mean & $\mathbf{C L}(\mathbf{9 5} \%)$ \\
\hline REff & 0.61 & $0.54-0.68$ & 0.71 & $0.68-0.74$ \\
\hline
\end{tabular}

correlated with IADL-E, decreasing from -0.53 to -0.65 (Table 4).

\section{Discussion}

VMS allowed assessment of the interaction between different domains of clinical phenomenology of AD. It determined that subjects with $A D$ performed worse in executive functioning as compared to healthy

\section{Statistical analysis} intergroup comparisons (Mann-Whitney test), (ii) analyse associations (Fisher's exact test), and (iii) assess associations (Spearman rank correlation). The confidence limit was set at 0.05.

\section{RESULTS}

The ratio of efficacy $\left(R E_{f f}\right)$ was lower in the $\mathrm{AD}$ group as compared to the healthy control group. Each functional impairment score differed between the two groups (Table 3). The differentiation between the AD and the healthy control group increased progressively when the cumulative impact of weights $\left(k_{1-4)}\right.$ was taken into account.

The impairment indices were positively correlated with MMSE with a progressive increase from 0.55 to 0.81 , and negatively
SPSS (version 19.0) was used to (i) perform

controls. These results are consistent with previous findings ${ }^{13-15}$. Esposito et al. ${ }^{16}$ found that AD patients had significantly more multitasking deficits than control subjects.

The VMS method defined an objective and continuous measure of functional impairment disturbances. The functional impairment score was strongly correlated (0.81) with the MMSE, even though the functional score included characteristics that are not included in the MMSE, such as repetition, omission and incorrect order. In addition, it correlated negatively with the IADL-E scale, the golden standard in clinical practice.

Basing the validation of the functional impairment score only on the final correlation between neuropsychological evaluation tools, and its ability to

Table 4. Correlation of impairment scores (Index $0-3, S\left(\boldsymbol{K}_{1-4}\right)$ with medical evaluation tools MMSE (Mini-Mental State Examination) and IADL-E (Instrumental Activity of Daily Living Evaluation); REff=Ratio of efficacy; $k_{1}=$ activity missed; $k_{2}=$ activity repeated; $k_{3}=$ incorrect order; $k_{4}=$ first attempt incorrect ; ${ }^{*}=$ significant at a confidence limit of $0.05 ; n=26$

\begin{tabular}{|c|c|c|}
\hline \multicolumn{2}{|l|}{ Correlation pair } & Spearmans's rho* \\
\hline \multirow[t]{5}{*}{ MMSE versus } & Index $0: \mathrm{RE}_{\mathrm{ff}}$ & 0.55 \\
\hline & Index $1: \mathrm{RE}_{\mathrm{ff}} \times \mathrm{k}_{1}{ }^{\mathrm{a} 1}$ & 0.59 \\
\hline & Index $2: \mathrm{RE}_{\mathrm{ff}} \times \mathrm{k}_{1}{ }^{\mathrm{a} 1} \times \mathrm{k}_{2}{ }^{\mathrm{a} 2}$ & 0.70 \\
\hline & Index ${ }_{3}: \operatorname{RE}_{f f} \times k_{1}{ }^{a 1} \times k_{2}{ }^{a 2} \times k_{3}{ }^{1-a} 3$ & 0.77 \\
\hline & Functional impairment: $\mathrm{S}\left(\mathbf{K}_{1-4}\right)$ & 0.81 \\
\hline \multirow[t]{5}{*}{ IADL-E versus } & Index $0: \mathrm{RE}_{\mathrm{ff}}$ & -0.53 \\
\hline & Index ${ }_{1}: \mathrm{RE}_{\mathrm{ff}} \times \mathrm{k}_{1}{ }^{\mathrm{a} 1}$ & -0.62 \\
\hline & Index $2: \mathrm{RE}_{\mathrm{ff}} \times \mathrm{k}_{1}^{\mathrm{a} 1} \times \mathrm{k}_{2}{ }^{\mathrm{a} 2}$ & -0.64 \\
\hline & Index ${ }_{3}: \mathrm{RE}_{\mathrm{ff}} \times \mathrm{k}_{1}{ }^{\mathrm{a} 1} \times \mathrm{k}_{2}{ }^{\mathrm{a} 2} \times \mathrm{k}_{3}{ }^{1-\mathrm{a} 3}$ & -0.65 \\
\hline & Functional impairment: $\mathrm{S}\left(\mathrm{K}_{1-4}\right)$ & -0.65 \\
\hline
\end{tabular}
discriminate healthy controls from AD participants, may be considered a limitation of the VMS method.

In addition, only part of the evaluation is automated. To avoid subjective interpretation of the scenario, a manual annotation was still required to identify start and end of each activity based on subjects' behaviour. Future research will study the capability 


\section{Functional dementia assessment}

of VMS to detect events with the same validity as a manual annotation.

In summary, we proved the concept of a functional impairment score for automated, objective and continuous measurement of cognitive and functional ability that is highly correlated with standard cognitive and functional assessments.

\section{Acknowledgment}

This study was supported by grant ANR- 09TECS-016-01-TecSan- SWEET HOME of the Innovation Alzheimer and ARMEP of Nice CHU member of CIU-S.

\section{References}

1. Dubois B, Feldman HH, Jacova C, Cummings JL, DeKosky ST, Barberger-Gateau P, Delacourte A, Frisoni G, Fox NC, Galasko G, Gauthier S, Hampel H, Jicha GA, Meguro K, O'Brien J, Pasquier F, Robert P, Rossor M, Salloway S, Sarazin M, Souza LC de, Stern Y, Visser PJ, Scheltens P. Revising the definition of Alzheimer's disease: a new lexicon. The Lancet Neurology 2010;9(11):1118-1127; doi:10.1016/S1474-4422(10)70223-4

2. Burns A. Meaningful treatment outcomes in Alzheimer's disease. Journal of Neurology, Neurosurgery and Psychiatry 2002;73(5):471472; doi:10.1136/jnnp.73.5.471

3. Sampaio C. Clinical relevance on Alzheimer's disease endpoints. Journal of Nutrition, Health and Aging 2007;11(4):316-317;

4. Olin JT, Schneider LS, Doody RS. Clark CM, Ferris SH, Morris JC, Reisberg B, Schmitt FA. Clinical evaluation of global change in Alzheimer's disease: identifying consensus. Journal of Geriatrics, Psychiatry and Neurology 1996;9(4):176-180

5. McKhann GM, Knopman DS, Chertkow H, Hyman BT, Jack Jr CR, Kawas CH, Klunk WE, Koroshetz WJ, Manly JJ, Mayeux R, Mohs RC, Morris JC, Rossor MN, Scheltens P, Carrillo MC, Thies B, Weintraub S, Phelps $\mathrm{CH}$. The diagnosis of dementia due to Alzheimer's disease: recommendations from the $\mathrm{Na}$ tional Institute on Aging-Alzheimer's Association workgroups on diagnostic guidelines for Alzheimer's disease. Alzheimer's and Dementia 2011;7(3):263-269; http://dx.doi. org/10.1016/j.jalz.2011.03.005

6. Marshall GA, Rentz DM, Frey MT, Locascio JJ, Johnson KA, Sperling RA. Instrumental activities of daily living impairment is associated with increased amyloid burden. Dementia and Geriatric Cognitive Disorders 2011;31(6):443-450; doi:10.1159/000329543

7. McKhann G, Drachman D, Folstein M, Katzman R, Price D, Stadlan EM. Clinical diagnosis of Alzheimer's disease: report of the NINCDS-ADRDA Work Group under the auspices of Department of Health and
Human Services Task Force on Alzheimer's Disease. Neurology 1984;34(7):939-944

8. Folstein MF, Folstein SE, McHugh PR. "Minimental state". A practical method for grading the cognitive state of patients for the clinician. Journal of Psychiatry Research 1975;12(3):189198

9. Robert $\mathrm{PH}$, Clairet $\mathrm{S}$, Benoit $\mathrm{M}$, Koutaich J, Bertogliati C, Tible O, Caci H, Borg M, Brocker $\mathrm{P}$, Bedoucha $\mathrm{P}$. The apathy inventory: assessment of apathy and awareness in Alzheimer's disease, Parkinson's disease and mild cognitive impairment. International Journal of Geriatric Psychiatry 2002;17(12):1099-1105

10. Montgomery SA, Asberg M. A new depression scale designed to be sensitive to change. British Journal of Psychiatry 1979;134(4):382389; doi:10.1192/bjp.134.4.382

11. Cummings JL, Mega M, Gray K, RosenbergThompson S, Carusi DA, Gornbein J. The Neuropsychiatric Inventory: comprehensive assessment of psychopathology in dementia. Neurology 1994;44(12):2308-2314

12. Mathuranath PS, George A, Cherion PJ, Mathew R, Sankarg Sarma P. Instrumental activities of daily living scale for dementia screening in elderly people. International Psychogeriatrics 2005;17(3):461-474

13. Marshall GA, Rentz DM, Frey MT, Locascio JJ, Johnson KA, Sperling RA. Executive function and instrumental activities of daily living in mild cognitive impairment and Alzheimer's disease. Alzheimer's and Dementia 2011;7(3):300-308; doi:10.1016/j. jalz.2010.04.005

14. Boyle PA, Malloy PF, Salloway S, Cahn-Weiner DA, Cohen R, Cummings JL. Executive dysfunction and apathy predict functional impairment in Alzheimer disease. American Journal of Geriatric Psychiatry 2003;11(2):214-221

15. Razani J, Casasa R, Wonga JT, Lub P, Alessic C, Josephson K. Relationship between executive functioning and activities of daily living in patients with relatively mild dementia. Applied Neuropsychology 2007;14(3):208-214; doi:10.1080/09084280701509125

16. Esposito $F$, Rochat $L$, Juillerat-van der Linden A-C, Lekeu F, Quittre A, Charnallet A, Linden $M$ van der. Apathy and executive dysfunction in Alzheimer disease. Alzheimer Disease and Associated Disorders 2010;24(2):131-137; doi:10.1097/WAD.0b013e3181c9c168 